\title{
Brain-Derived Neurotrophic Factor Produces Antidepressant Effects in Behavioral Models of Depression
}

\author{
Yukihiko Shirayama, Andrew C.-H. Chen, Shin Nakagawa, David S. Russell, and Ronald S. Duman \\ Division of Molecular Psychiatry, Abraham Ribicoff Research Facilities, Connecticut Mental Health Center, Yale University \\ School of Medicine, New Haven, Connecticut 06508
}

\begin{abstract}
Previous studies demonstrated that antidepressant treatment increases the expression of brain-derived neurotrophic factor (BDNF) in rat hippocampus. The present study was conducted to test the hypothesis that BDNF in the hippocampus produces an antidepressant effect in behavioral models of depression, the learned helplessness (LH) and forced swim test (FST) paradigms. A single bilateral infusion of BDNF into the dentate gyrus of hippocampus produced an antidepressant effect in both the LH and FST that was comparable in magnitude with repeated systemic administration of a chemical antidepressant.
\end{abstract}

These effects were observed as early as $3 \mathrm{~d}$ after a single infusion of BDNF and lasted for at least $10 \mathrm{~d}$. Similar effects were observed with neurotrophin-3 (NT-3) but not nerve growth factor. Infusions of BDNF and NT-3 did not influence locomotor activity or passive avoidance. The results provide further support for the hypothesis that BDNF contributes to the therapeutic action of antidepressant treatment.

Key words: neurotrophin-3; nerve growth factor; dentate gyrus; learned helplessness; forced swim test; hippocampus; MAP kinase
Depression is a devastating illness that affects $\sim 17 \%$ of the population at some point in life, resulting in major social and economic consequences (Kessler et al., 1994). Significant progress has been made in our ability to treat depression, but not all depressed patients respond to available antidepressants, and the therapeutic response requires several weeks or months of treatment (Duman et al., 2000; Wong and Licinio, 2001). In addition, there is still very little known about the neurobiological alterations that underlie the pathophysiology or treatment of depression.

In recent years, research has been directed at sites beyond the level of monoamines and receptors to examine potential postreceptor mechanisms in the action of antidepressant treatment. These studies have identified adaptations of intracellular signaling proteins and target genes that could contribute to the action of antidepressant treatment (Altar, 1999; Duman et al., 2000; Manji et al., 2000; Wong and Licinio, 2001). One target gene of antidepressant treatment is brain-derived neurotrophic factor (BDNF). Antidepressant treatment increases the expression of BDNF in limbic structures, most notably the hippocampus (Nibuya et al., 1995, 1996; Rosello-Neustadt and Cotman, 1999). Upregulation of BDNF occurs in response to chronic but not acute antidepressant treatment, consistent with the time course for the therapeutic action of antidepressants. The possibility that $\mathrm{BDNF}$ is also involved in the pathophysiology of stress-related mood disorders is supported by reports that BDNF expression is decreased by exposure to stress (Smith et al., 1995; Nibuya et al., 1999). Clinical brain-imaging studies demonstrate that the vol-

\footnotetext{
Received Sept. 20, 2001; revised Jan. 25, 2002; accepted Feb. 1, 2002.

This work is supported by United States Public Health Service Grants MH45481 and 2 PO1 MH25642, a Veterans Administration National Center grant for posttraumatic stress disorder, and the Connecticut Mental Health Center.

Correspondence should be addressed to Ronald S. Duman, Division of Molecular Psychiatry, Abraham Ribicoff Research Facilities, Connecticut Mental Health Center, Yale University School of Medicine, 34 Park Street, New Haven, CT 06508. E-mail: ronald.duman@yale.edu.

Copyright (C) 2002 Society for Neuroscience $\quad 0270-6474 / 02 / 223251-11 \$ 15.00 / 0$
}

ume of the hippocampus is decreased in depressed patients, consistent with the possibility of reduced neurotrophic factor support or synaptic remodeling in depression (Sheline et al., 1996, 1999; Bremner et al., 2000).

BDNF and other members of the neurotrophic factor family, including nerve growth factor (NGF) and neurotrophin-3 (NT-3), influence cellular function via activation of their respective tyrosine kinase receptors and one of at least three effector systems (Chang and Karin, 2001; Sweatt, 2001). One of the bestcharacterized neurotrophin-activated signal transduction pathways is the mitogen-activated protein (MAP) kinase cascade, which includes extracellular signal-regulated protein kinase (ERK) as one of the key steps in the pathway (Chang and Karin, 2001; Sweatt, 2001). A recent postmortem study reports that levels of ERK activity and expression are decreased in hippocampus and cerebral cortex of depressed suicide patients, providing additional support that neurotrophic factor function is downregulated in depression (Dwivedi et al., 2001).

The results of these basic and clinical studies indicate that regulation of BDNF expression and function in hippocampus could contribute to the pathophysiology and treatment of depression. To test this hypothesis, we have examined the influence of inf usions of BDNF into hippocampus on two behavioral models of depression, the learned helplessness ( $\mathrm{LH}$ ) paradigm and the forced swim test (FST). Both are well established paradigms that are responsive to antidepressant treatment (Seligman and Beagley, 1975; Porsolt et al., 1977). In addition, animals exposed to inescapable stress in the LH paradigm exhibit effects that are seen in depression, including decreased motor activity, loss of appetite, weight loss, anhedonia, and immunosuppression (Thiébot et al., 1992; Weiss and Kilts, 1995). A previous study has reported that infusion of BDNF into the midbrain results in an antidepressantlike effect in the LH and FST models (Siuciak et al., 1997). The current study examines the influence of BDNF infusions into the hippocampus where the expression of this neurotrophic factor is regulated by stress and antidepressant treatment. 


\section{MATERIALS AND METHODS}

Intrahippocampus surgery. Animal use procedures were in accordance with the National Institutes of Health Guide for the Care and Use of Laboratory Animals and were approved by the Yale University Animal Care and Use Committee. Male Sprague Dawley rats (225-300 gm; Charles River, Wilmington, MA) were used. The animals were housed under a $12 \mathrm{hr}$ light/dark cycle with ad libitum access to food and water. Surgery was performed in a stereotaxic apparatus (Kopf, Tujunga, CA) under anesthesia with pentobarbital sodium solution $(50 \mathrm{mg} / \mathrm{kg}$, i.p.; Abbott Laboratories, North Chicago, IL). Rats received bilateral microinjection of different amounts of $\operatorname{BDNF}(0.05,0.25$, and $1.0 \mu \mathrm{g} / \mathrm{side})$, NT-3 $(0.25 \mu \mathrm{g} / \mathrm{side})$, NGF $(0.25 \mu \mathrm{g} / \mathrm{side})$, or saline $(0.9 \%)$ into the dentate gyrus and $\mathrm{CA} 3$ and $\mathrm{CA} 1$ regions of hippocampus. A total volume of $1.0 \mu \mathrm{l}$ was infused into each side over $15 \mathrm{~min}$, and the injection syringe was left in place for an additional $5 \mathrm{~min}$ to allow for diffusion. In some experiments, a nonspecific tyrosine kinase inhibitor, K252a ( $0.5 \mathrm{ng} / \mathrm{side})$, was co-inf used bilaterally with BDNF, or an MAP kinase kinase (MEK) inhibitor, U0126 (0.1 $\mathrm{gg}$ in $1 \mu \mathrm{l}$ of $1 \%$ DMSO), was infused bilaterally 20 min before infusion of BDNF. The coordinates for the dentate gyrus, CA3, and CA1 (relative to bregma according to the atlas of Paxinos and Watson, 1997) were as follows: -3.8 anteroposterior (AP), \pm 2.0 lateral, and -3.1 dorsoventral (DV) from dura (dentate gyrus); $-3.8 \mathrm{AP}, \pm 3.8$ lateral, and $-3.2 \mathrm{DV}$ from dura (CA3); and $-3.8 \mathrm{AP}, \pm 2.0$ lateral, and $-2.5 \mathrm{DV}$ from dura (CA1). In one experiment, three injections were made into different anteroposterior sites in the dentate gyrus (bregma, $-3.3,-3.8$, and $-4.3 \mathrm{AP}, \pm 2.0$ lateral, and $-3.0 \mathrm{DV}$ from dura). For the learned helplessness experiments, animals received surgery $1 \mathrm{~d}$ after the postshock screening test (see below). For the forced swim and open field tests, surgery was performed $3 \mathrm{~d}$ before the first day of a $15 \mathrm{~min}$ swim-training session and open field test (see below). After the behavioral tests, the rats were killed by decapitation. The brains were removed and stored at $-80^{\circ} \mathrm{C}$ until use. Frozen sagittal sections were cut by cryostat, and cresyl violet staining was conducted to determine the placement of the injection syringe. Any behavioral test data generated from animals in which the syringe track was not in the correct area were excluded.

Learned helplessness paradigm. In this paradigm, an animal is initially exposed to uncontrollable stress. When the animal is later placed in a situation in which shock is controllable (escapable), the animal not only fails to acquire the escape responses but also often makes no efforts to escape the shock at all. This escape deficit is reversed by chronic antidepressant treatment (Chen et al., 2001). Learned helplessness behavioral tests were performed with the Gemini avoidance system (San Diego Instruments, San Diego, CA). This apparatus was divided into two compartments by a retractable door. On day 1 , rats were subjected to 60 inescapable electric foot shocks $(0.8 \mathrm{~mA} ; 15 \mathrm{sec}$ duration; average interval, $45 \mathrm{sec}$ ). On day 2, a two-way conditioned avoidance test was performed as a postshock test to determine whether the rats would show the predicted escape deficits. This screening session consisted of 30 trials in which an electric foot shock $(0.8 \mathrm{~mA} ; 3 \mathrm{sec}$ duration, at random intervals; mean, $30 \mathrm{sec}$; average, 22-38 sec) was preceded by a $3 \mathrm{sec}$ conditioned stimulus tone that remained on until the shock was terminated. Rats with $>20$ escape failures in the 30 trails were regarded as having reached the criterion and were used for further experiments. Approximately $75 \%$ of the rats reached this criterion. For antidepressant treatments, imipramine $(10 \mathrm{mg} / \mathrm{kg}$, i.p., twice per day), fluoxetine $(10 \mathrm{mg} / \mathrm{kg}$, i.p., once per day), or saline (once per day) was administrated $1 \mathrm{~d}$ after the postshock screening test for $7 \mathrm{~d}$ until $1 \mathrm{~d}$ before the active avoidance behavioral tests were performed. For neurotrophic factor infusions, $1 \mathrm{~d}$ after the postshock test, rats received bilateral microinjections of BDNF, NT-3, NGF, or vehicle as described above. At day 6 (3 d after the surgery) or day 13 (10 d after the surgery), a two-way conditioned avoidance test was performed. This test session consisted of 30 trials in which an electric foot shock $(0.8 \mathrm{~mA}$; $30 \mathrm{sec}$ duration, at random intervals; mean, $30 \mathrm{sec}$; average, 22-38 sec) was preceded by a $3 \mathrm{sec}$ conditioned stimulus tone that remained on until the shock was terminated. The numbers of escape failures and escape latency in each 30 trials was recorded by the Gemini avoidance system.

In a later experiment to examine the effects of U0126, the parameters for the LH paradigm were adjusted to obtain a higher percentage of animals that reached the criterion of 20 or more failures in 30 trials. On day 1 , animals received sixty $0.65 \mathrm{~mA}$ shocks of $30 \mathrm{sec}$ duration. The postshock test on day 2 was conducted as described above, except there were 20 trials at $0.65 \mathrm{~mA}$. An additional inescapable shock was administered on day 2 to reinforce the $\mathrm{LH}$ condition. This consisted of twenty
$0.65 \mathrm{~mA}$ shocks of $30 \mathrm{sec}$ duration. This paradigm increased the number of animals reaching criterion to $80-90 \%$. Finally, on day 6 , the two-way active avoidance test was conducted as described above, except the current was set at $0.65 \mathrm{~mA}$ instead of $0.80 \mathrm{~mA}$. Infusions of BDNF produced an antidepressant effect under both paradigms (see Results).

Forced swim test. This paradigm was performed as described previously (Porsolt et al., 1977; Siuciak et al., 1997). This is a standard test used to screen compounds for an antidepressant-like effect. On day 1 (3 d after the surgery for infusions of neurotrophins) the animals were placed in a container with water at a depth of $40 \mathrm{~cm}\left(23-25^{\circ} \mathrm{C}\right)$ for $15 \mathrm{~min}$. At this depth, the rats cannot touch the bottom with their hind limbs or tail. On day 2 , the rats were placed back into the water for $10 \mathrm{~min}$, and the sessions were videotaped. The $10 \mathrm{~min}$ session on day 2 was subdivided into two $5 \mathrm{~min}$ intervals. The three behaviors scored are defined as follows (Lucki, 1997); (1) climbing, with the rat making a active attempt to escape from the tank, including visual searching for the escape routes and diving; climbing may be more related to attempts to escape than is swimming (Lucki, 1997); (2) swimming, with the rat staying afloat, pedaling, and making circular movements around the tank; and (3) immobility, with the rat not making any active movements.

Open field test. Three days after the surgery, spontaneous locomotor activity was measured in the open field test in a square arena $(76.5 \times$ $76.5 \times 49 \mathrm{~cm}$ ) using a standard procedure (Lacroix et al., 1998). The open field was divided into two areas, a peripheral area and a square center $(40 \times 40 \mathrm{~cm})$. Rats were allowed to explore for $30 \mathrm{~min}$. The test room was dimly illuminated (two $60 \mathrm{~W}$ lights, indirect). The computer software (EthoVision; Noldus) calculated the velocity of movement, the distance of traveling, and the time spent in the center of the open field. These parameters are thought to reflect locomotor activity and fear or anxiety, respectively.

Passive avoidance test. Passive avoidance was conducted according to standard procedures with the following modifications (Ferry et al., 1999). The apparatus was divided into two compartments by a retractable door: a lit safe compartment and a darkened shock compartment (Gemini avoidance test). Three days after the surgery, animals received a single inescapable foot shock $(0.8 \mathrm{~mA} ; 1.0 \mathrm{sec}$ duration $)$. Twenty-four hours later, each rat was placed in the safe compartment, and the latency to reenter the darkened shock compartment with all four paws was recorded as the measure of retention.

Immunocytochemistry. At different time points after infusion of BDNF $(0.5,2,4,24$, and $72 \mathrm{hr})$ animals were perfused. All rats were placed under deep chloral hydrate anesthesia and killed via intracardial perfusion with $4 \%$ paraformaldehyde in $1 \times \mathrm{PBS}, \mathrm{pH} 7.4$. Brains were removed, post-fixed overnight in the same fixative (with shaking) at $4^{\circ} \mathrm{C}$, and stored at $4^{\circ} \mathrm{C}$ in $30 \%$ sucrose. Serial coronal sections of the brains were cut (35 $\mu \mathrm{m}$ sections) through hippocampus on a freezing microtome, and sections were stored at $4^{\circ} \mathrm{C}$ in $1 \times$ PBS containing $0.1 \%$ sodium azide.

BDNF immunocytochemistry was performed as described previously (Mamounas et al., 2000; Dawson et al., 2001). Free-floating sections were washed three times for $5 \mathrm{~min}$ in $1 \times$ PBS and then incubated for $10 \mathrm{~min}$ in $1 \times$ PBS containing $0.6 \%$ hydrogen peroxide to eliminate endogenous peroxidases. After washing three times for $5 \mathrm{~min}$ in $1 \times \mathrm{PBS}$, sections were then incubated for $1 \mathrm{hr}$ in $1 \times \mathrm{PBS}$ containing $2 \%$ bovine serum albumin (BSA), 5\% normal goat serum, and $0.2 \%$ Triton $\mathrm{X}-100$ for blocking. Sections were incubated at $4^{\circ} \mathrm{C}$ for $72 \mathrm{hr}$ with primary BDNF rabbit polyclonal antibody (1:1000; Chemicon, Temecula, CA). After washing six times for $5 \mathrm{~min}$ in $1 \times$ PBS, sections were incubated for $2 \mathrm{hr}$ with secondary antibody (biotinylated goat anti-rabbit; Vector Laboratories, Burlingame, CA) followed by amplification with an avidin-biotin complex (Vectastain Elite ABC kit; Vector Laboratories) and were visualized with DAB (Vector Laboratories).

Phospho-ERK (pERK) and Fos immunocytochemistry was performed as described previously with minor modifications (Sgambato et al., 1998). For pERK, free-floating sections were treated as described for BDNF immunohistochemistry and then were incubated at $4^{\circ} \mathrm{C}$ for $72 \mathrm{hr}$ with primary pERK rabbit polyclonal antibody (1:500; Promega, Madison, WI). For Fos, sections were prepared as described above and then incubated for $1 \mathrm{hr}$ in $1 \times \mathrm{PBS}$ containing $2 \% \mathrm{BSA}, 5 \%$ normal horse serum, and $0.2 \%$ Triton X-100 for blocking. Sections were incubated at $4^{\circ} \mathrm{C}$ for $72 \mathrm{hr}$ with primary Fos goat polyclonal antibody $(1: 300$; Santa Cruz Biotechnology, Santa Cruz, CA). After washing six times for $5 \mathrm{~min}$ in $1 \times$ PBS, sections for both pERK and Fos were incubated for $2 \mathrm{hr}$ with secondary antibody (biotinylated goat anti-rabbit or goat anti-goat, resectively; Vector Laboratories) followed by amplification with an avidin- 
biotin complex (Vectastain Elite ABC kit). Immunolabeled sections were visualized with DAB.

Statistical analysis. Statistical differences among more than three groups were estimated by a one-way ANOVA, followed by Scheffe's test. For comparison of the mean values between the two groups, statistical evaluation was done using the two-tailed Student's $t$ test. For the forced swimming test, two-way repeated measures ANOVA was performed to assess the overall differences for each behavior between the groups on day 1 of pretest and on day 2 . When a significant interaction in the between-subjects variables (treatment and time) was determined, a subsequent one-way ANOVA was performed.

\section{RESULTS}

\section{Infusion of BDNF into the hippocampus decreases escape failure in the learned helplessness paradigm}

In the learned helplessness paradigm, rats that have been exposed to inescapable foot shock (IES) exhibit a deficit in escape performance on subsequent conditioned avoidance behavior. Of 30 trials, animals exposed to IES failed to escape $\sim 20-25$ times, with an escape latency of $\sim 25-30 \mathrm{sec}$ (Fig. 1). Animals not exposed to IES readily escaped at a much higher rate (approximately five failures, with an escape latency of $\sim 5-10 \mathrm{sec}$; data not shown) (Siuciak et al., 1997; Chen et al., 2001). Subchronic administration of an antidepressant significantly improves the ability of the animals to escape in the conditioned avoidance test. This effect was observed in the current study with administration either of a tricyclic antidepressant, imipramine, or a 5-HTselective reuptake inhibitor, fluoxetine (Fig. 1). These results demonstrate that the learned helplessness paradigm is responsive to antidepressant treatment as reported previously (Siuciak et al., 1997; Chen et al., 2001).

The effect of bilateral microinjections into the hippocampus of BDNF, as well as other members of the neurotrophin family, NGF and NT-3, was determined. Antidepressant treatment produces a robust upregulation of BDNF in the dentate gyrus granule cell layer (Nibuya et al., 1995), and neurotrophic factor infusions in this subfield of hippocampus were tested first. For these studies and all subsequent experiments, the neurotrophic factors were infused bilaterally into the hippocampus $1 \mathrm{~d}$ after IES, and $3 \mathrm{~d}$ later the animals were subjected to conditioned avoidance testing. Rats that received bilateral microinjection of BDNF or NT-3, but not NGF, into the dentate gyrus of hippocampus demonstrated a significant improvement in the conditioned avoidance test relative to vehicle-treated controls (Fig. 1). This was measured as a significant decrease in failure number and latency to escape in conditioned avoidance testing and was similar to the effects of antidepressant treatment. Different doses of BDNF were also tested, demonstrating a significant improvement in escape performance at 0.25 and $1.0 \mu \mathrm{g}$ but not at $0.05 \mu \mathrm{g}$ per side (Fig. 1). The influence of neurotrophic factor infusion into other subfields of hippocampus was also examined. Infusion of BDNF, but not NT-3 or NGF, into the CA3 pyramidal cell layer also significantly improved performance in the conditioned avoidance test (Fig. 2). In contrast, none of the neurotrophic factors tested improved escape behavior when infused into the CA1 pyramidal cell layer (Fig. 2). The results demonstrate that the reversal of escape failure is neurotrophic factor-specific (BDNF and NT-3 but not NGF), is dose-dependent (e.g., BDNF), and is region-specific.

Next we conducted an experiment to determine whether the effect of BDNF on conditioned avoidance is long-lasting. Instead of $3 \mathrm{~d}$ after infusion of BDNF, conditioned avoidance was conducted 10 d later (Fig. 3). Surprisingly, escape behavior was still significantly improved even $10 \mathrm{~d}$ after bilateral BDNF infusion at a single level of dentate gyrus. Longer periods could not be tested, because we found that there is a tendency for spontaneous recovery of escape $14 \mathrm{~d}$ after IES training (Chen et al., 2001; Maier, 2001). Studies were also conducted to determine the
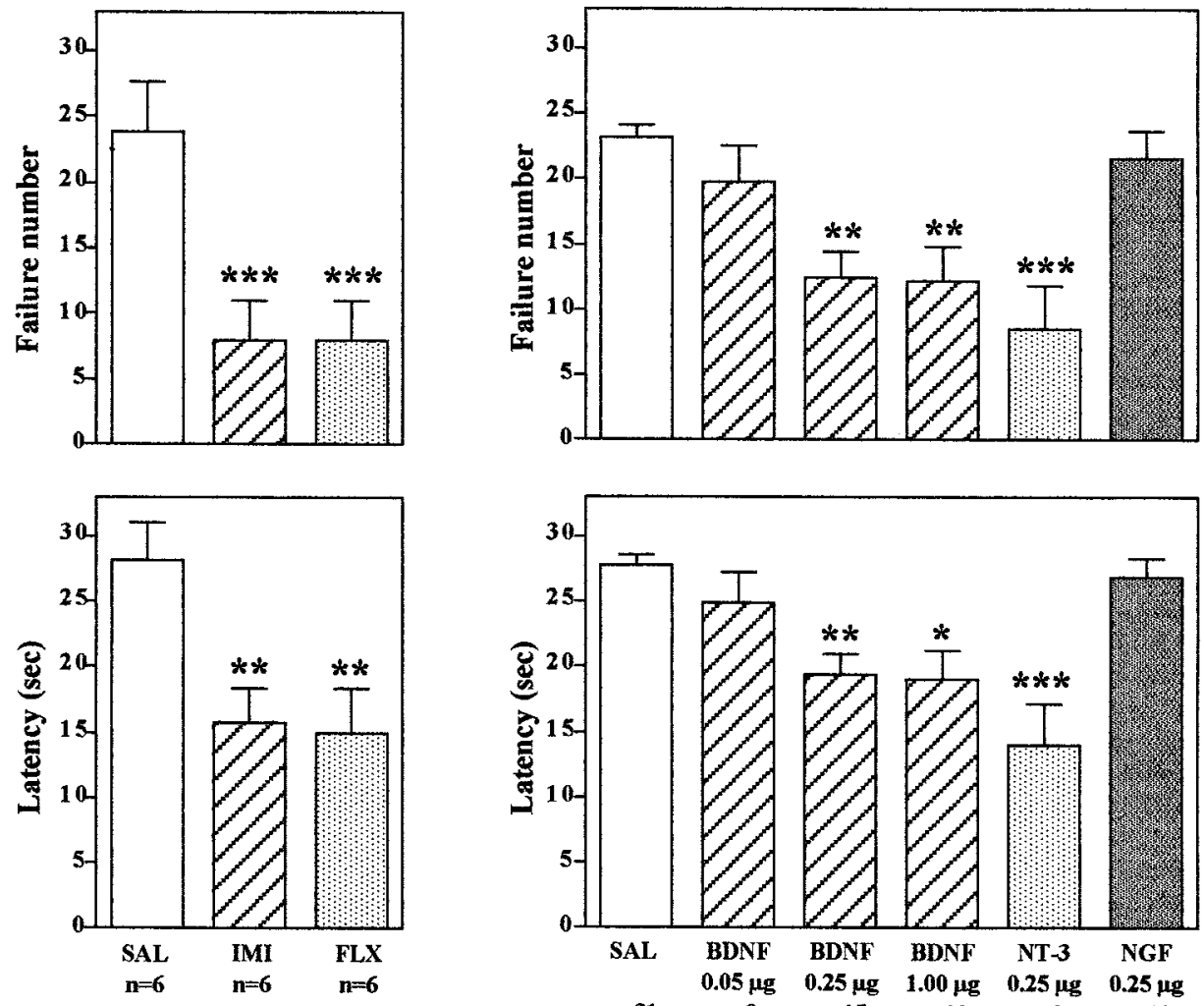

Figure 1. Inf usion of BDNF into the dentate gyrus of hippocampus decreases escape failure in the $\mathrm{LH}$ paradigm. Animals were exposed to IES as described in Materials and Methods and then were administered the antidepressants or neurotrophic factors as indicated before conditioned avoidance testing. Imipramine (IMI) and fluoxetine $(F L X)$ were administered for $7 \mathrm{~d}$. BDNF, NT-3, NGF, or saline $(S A L)$ was administered via bilateral infusion into the dentate gyrus at the doses indicated, and animals were tested in conditioned avoidance $3 \mathrm{~d}$ later. Escape failure and latency to escape were determined, and the results are expressed as mean \pm SEM. The number of animals is listed under each column. ${ }^{*} p<0.05$; ** $p<0.01$; *** $p<0.001$ when compared with saline-injected controls (ANOVA and Scheffe's test). Left top, $F_{(2,15)}=$ $15.38 ; p=0.0002$; left bottom, $F_{(2,15)}=9.282$; $p=0.0024 ;$ right top, $F_{(5,77)}=10.050 ; p<$ $0.0001 ;$ right bottom, $F_{(5,77)}=10.872 ; p<$ 0.0001 . 

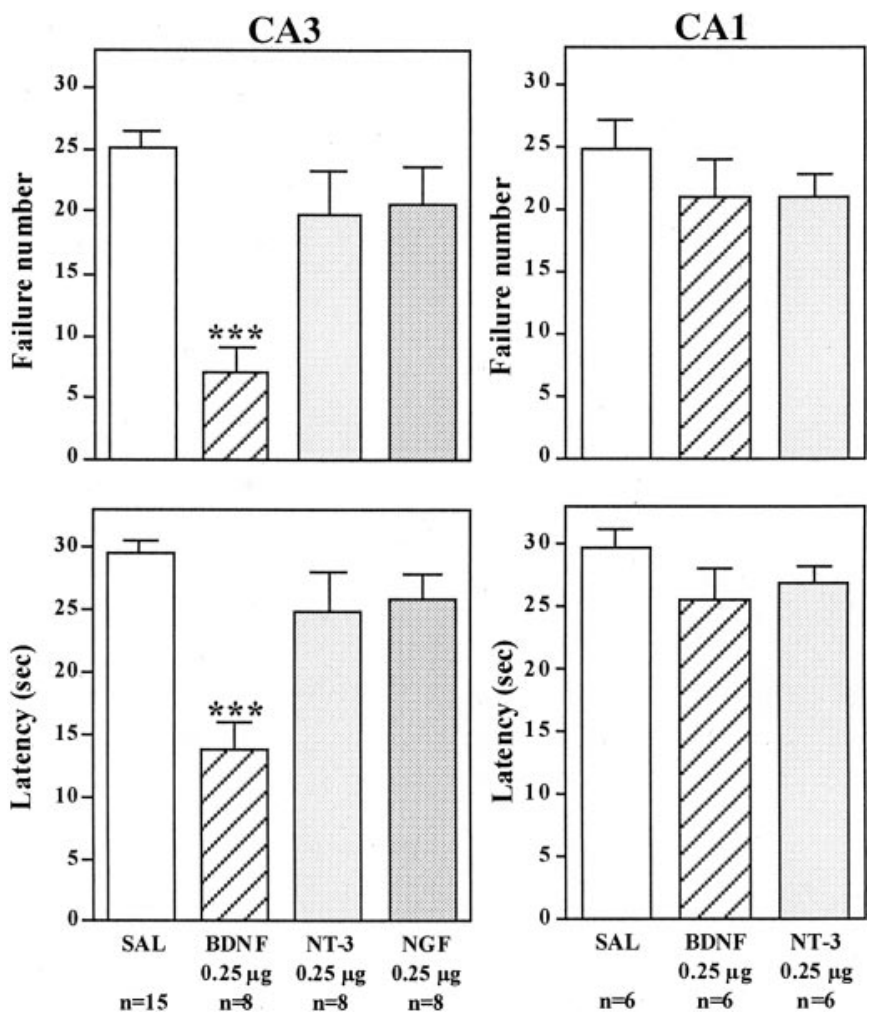

Figure 2. Influence of neurotrophic factor infusions into the CA3 and CA1 pyramidal cell layers on the LH paradigm. After exposure to IES, BDNF, NT-3, NGF, or saline ( $S A L)$ was infused into the CA3 or CA1 pyramidal cell layers of hippocampus, and conditioned avoidance was conducted 3 d later. Escape failure and latency to escape were determined, and the results are expressed as mean \pm SEM. The number of animals is listed under each column. ${ }^{* *} p<0.001$ when compared with saline-injected controls (ANOVA and Scheffe's test). Left top, $F_{(3,33)}=$ $12.667 ; p<0.0001$; left bottom, $F_{(3,33)}=12.045 ; p<0.0001$; right top, $F_{(2,15)}=0.824 ; p=0.4575 ;$ right bottom, $F_{(2,15)}=1.292 ; p=0.3037$.

influence of multiple infusions of BDNF on conditioned avoidance and the time course of this effect. Because of the relatively large molecular weight of the neurotrophic factors $(\sim 13 \mathrm{kDa})$, diffusion from a single site of injection would not be expected to influence a very large area of the hippocampus (see below). To determine whether more injections of BDNF could produce a more robust blockade of escape deficits, bilateral infusions were made at three anteroposterior levels of dentate gyrus, separated by $0.5 \mathrm{~mm}(0.25 \mu \mathrm{g} /$ inf usion site $)$. This multiple injection paradigm significantly improved performance in the conditioned avoidance test, but the effect was not greater than that observed after infusions at one level of dentate gyrus (Fig. 3).

\section{Infusion of BDNF into the hippocampus decreases immobility in the forced swim test}

The influence of neurotrophic factor infusions on behavior in another model of depression, the FST, was also determined. In this model, the immobility that occurs after rats or mice are placed in a container of water is reversed by antidepressant treatment (Porsolt et al., 1977), and this effect has been replicated in our laboratory (Chen et al., 2001). Recent studies also demonstrate that in addition to immobility behavior, the FST can be further characterized on the basis of the time animals spend swimming or climbing at the edge of the tank (Lucki, 1997).

In the current study, the effects of neurotrophic factor infusions on immobility, swimming, and climbing were determined. BDNF, $\mathrm{NT}-3$, or NGF $(0.25 \mu \mathrm{g} / \mathrm{side})$ was infused bilaterally into the dentate gyrus, and 3 d later animals were tested. Neurotrophic factor infusion did not influence immobility measured when animals were first exposed to water during the training session on the first day (data not shown). However, infusions of BDNF or NT-3 into the dentate gyrus significantly decreased immobility and increased swimming on the next, test day (Fig. 4). These effects were observed during both the first and second 5 min time blocks. There was a tendency for climbing behavior to be increased, although this effect was not significant. In contrast, infusion of NGF into the dentate gyrus did not influence any of the behaviors measured. Bilateral infusion of BDNF, but not NT-3, into the CA3 pyramidal cell layer significantly decreased immobility and increased swimming time (Fig. 4). In general, the neurotrophic factor selectivity and regional specificity observed in the FST were similar to those found in the LH paradigm. Because of these similarities, the effects of NGF infusions into the CA3 pyramidal cell layer or of any of the neurotrophic factors into the CA1 pyramidal cell layer were not determined.

\section{Influence of BDNF on additional behavioral tests}

Studies were conducted to determine the behavioral specificity of BDNF infusions into the hippocampus. First, the influence of

\section{$10 \mathrm{~d}$ after BDNF}
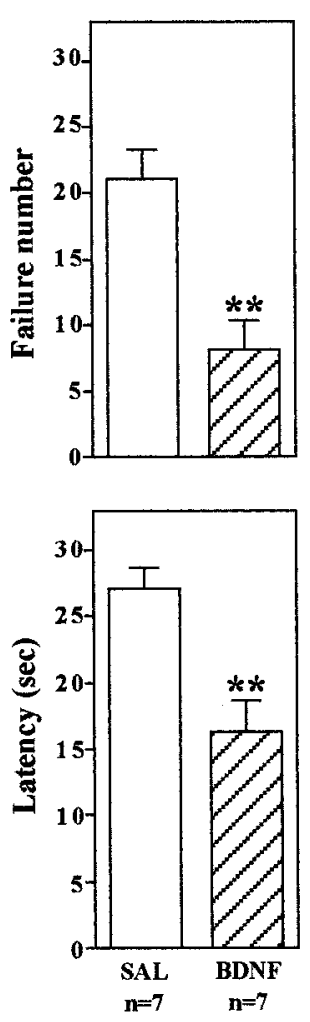

\section{BDNF infusions}
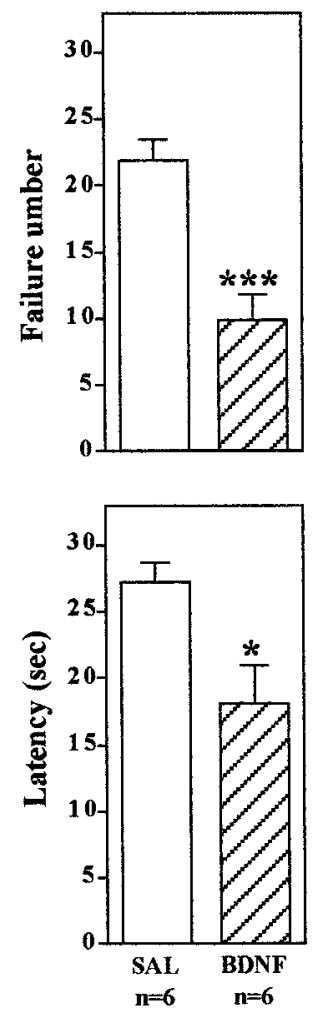

Figure 3. BDNF regulation of LH behavior: long-term effects and multiple infusions. The LH paradigm was conducted as described in Materials and Methods, except conditioned avoidance testing was conducted $10 \mathrm{~d}$ after BDNF infusion into the dentate gyrus (left) or $3 \mathrm{~d}$ after infusions at three different rostrocaudal levels of dentate gyrus (right). The results are expressed as mean \pm SEM. The number of animals is listed under each column. ${ }^{*} p<0.05$; ${ }^{*} p<0.01$; *** $p<0.001$ when compared with saline-injected controls (Student's $t$ test). Left top, $F_{(1,12)}=$ $4.172 ; p=0.0013$; left bottom, $F_{(1,12)}=4.022 ; p=0.0017$; right top, $F_{(1,10)}=4.824 ; p=0.0007 ;$ right bottom, $F_{(1,10)}=2.853 ; p=0.0172$. 


\section{Dentate gyrus}
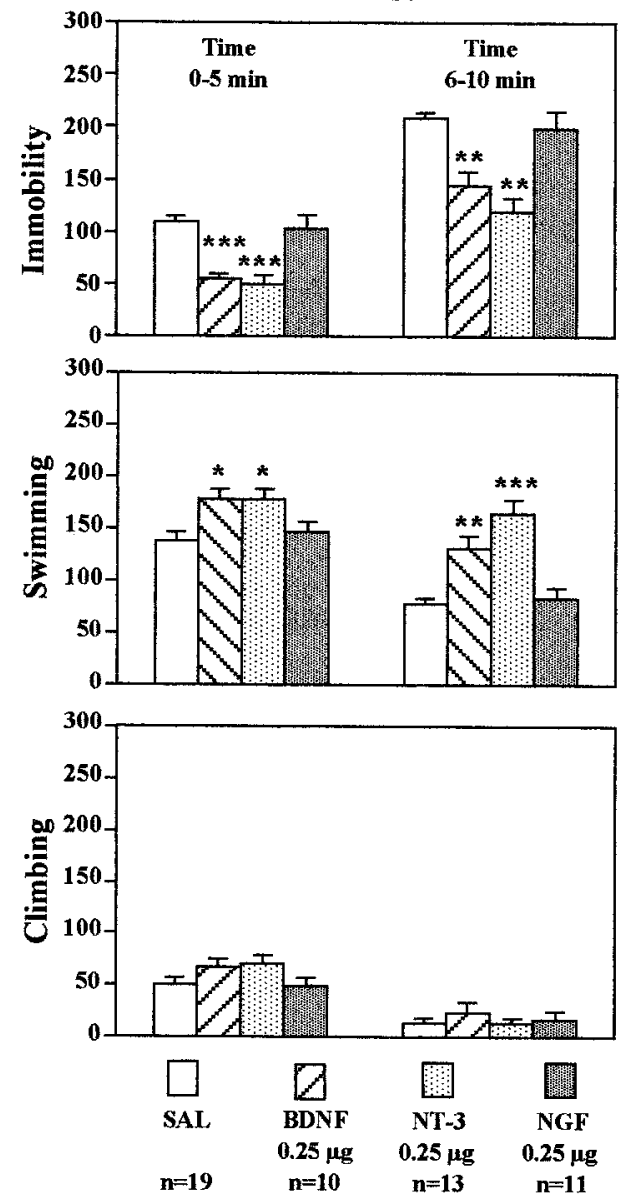

CA3
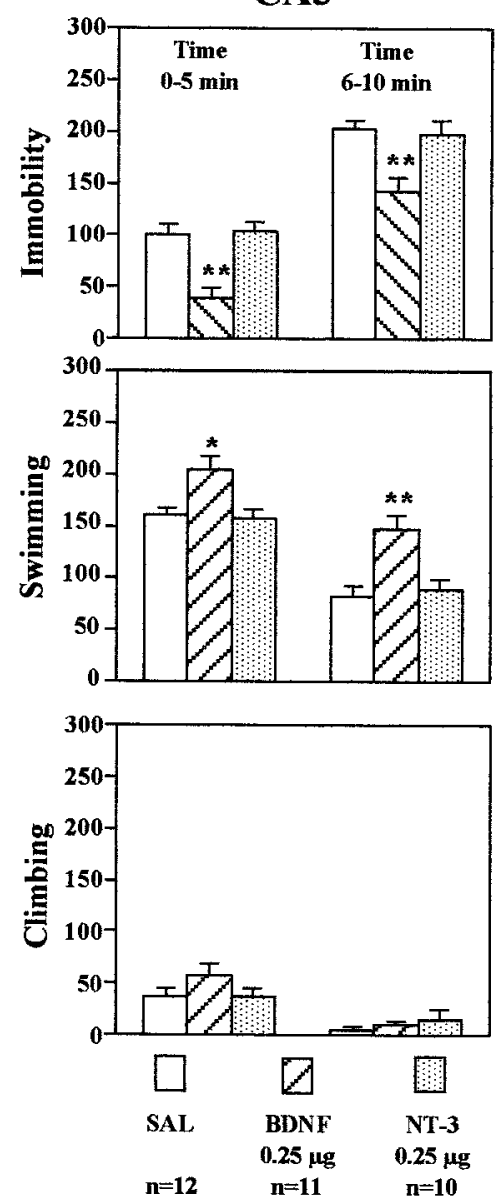

Figure 4. Infusion of BDNF into the hippocampus has an antidepressant effect in the FST. BDNF, NT-3, NGF, or saline (SAL) was infused into the dentate gyrus or CA3 as indicated. Three days later, the durations of immobility, swimming, and climbing in the FST were determined. The results are divided into two 5 min time blocks as indicated and are the mean \pm SEM of the number of animals indicated under each column. ${ }^{*} p<$ $0.05 ;{ }^{* *} p<0.01 ;{ }^{* * *} p<0.001$ when compared with the corresponding saline-injected controls (ANOVA and Scheffe's test). Left top, Immobility time, $0-5$ min, $F_{(3,49)}=16.348 ; p<0.0001$; immobility time, $6-10 \mathrm{~min}, F_{(3,49)}=15.823 ; p<0.0001$; left middle, swimming time, $0-5 \mathrm{~min}, F_{(3,49)}=$ 4.997; $p=0.0042$; swimming time, $6-10 \mathrm{~min}$, $F_{(3,49)}=18.025 ; p<0.0001 ;$ left bottom, climbing time, $0-5 \min , F_{(3,49)}=1.807 ; p=0.1582$; climbing time, $6-10 \mathrm{~min}, F_{(3,49)}=0.477 ; p=0.7001$; right top, immobility time, $0-5$ min, $F_{(2,30)}=15.749 ; p<$ 0.0001 ; immobility time, $6-10$ min, $F_{(2,30)}=8.219$; $p=0.0014$; right middle, swimming time, $0-5 \mathrm{~min}$, $F_{(2,30)}=6.811 ; p=0.0036$; swimming time, $6-10$ min, $F_{(2,30)}=10.129 ; p=0.0004$; right bottom, climbing time, $0-5 \mathrm{~min}, F_{(2,30)}=1.243 ; p=0.3031$; climbing time, $6-10 \mathrm{~min}, F_{(2,30)}=0.812 ; p=$ 0.4536 . There were no significant treatment $\times$ time interactions. neurotrophic factor inf usions into the hippocampus on activity in an open field was determined. The time spent in the center as well as the distance and velocity traveled were determined. Time spent in the center of a novel open field is also taken as one measure of anxiety (Lacroix et al., 1998). Infusions of BDNF or NT-3 into the dentate gyrus or CA3 subregions of hippocampus, treatments that produced antidepressant effects in the FST and LH paradigms, did not significantly influence time in the center, distance, or velocity of locomotor activity (Fig. 5). There was a tendency for BDNF infusions to decrease distance traveled and velocity. This would be opposite to the results expected if a general increase in locomotor activity were to contribute to the effect of BDNF on immobility and conditioned avoidance in the FST and LH models of depression. Infusions of NGF into either dentate gyrus or CA3 subfields did not influence behavior in the open field test.

We have also examined the influence of neurotrophic factor inf usions on passive avoidance. For this test, a two-compartment box is used in which one compartment is illuminated and the other is darkened. A single inescapable foot shock is administered on day 1 in the darkened compartment. Twenty-four hr later, animals are placed in the illuminated compartment and allowed to choose between either compartment. The darkened compartment is preferred, and the time spent in the illuminated side is a measure of retention of the memory of the foot shock on the darkened side. Infusions of BDNF, NT-3, or NGF into the dentate gyrus failed to change the time spent in the darkened compartment in the $24 \mathrm{hr}$ retention test (Fig. 6). Similarly, infu- sions of BDNF or NT-3 into the CA3 pyramidal cell layer of hippocampus did not alter the time in the darkened compartment in the retention test (Fig. 6). These results provide additional support that BDNF and NT-3 infusions do not cause a general increase in behavior that could result in the effects observed in the FST and LH paradigms. If this were the case, we would have expected to see a decrease in the latency to cross from the illuminated side to the darkened side in the passive avoidance test.

\section{Analysis of BDNF and phospho-ERK immunoreactivity}

The regulation of behavior in the $\mathrm{LH}$ and FST is somewhat surprising given the limited diff usion that would be expected after local infusion of a neurotrophic factor into hippocampus. As discussed above, this prompted our experiments to examine the influence of multiple infusion sites on LH behavior (Fig. 3). To directly address this point, studies were conducted to determine the extent of BDNF diff usion by immunohistochemical analysis. In addition, the functional consequences of BDNF were examined by analysis of pERK and Fos immunolabeling, both of which are increased by activation of neurotrophic factor receptors.

Immunolabeling of endogenous BDNF was observed in the major subfields of hippocampus in saline-infused controls, as reported previously (Fig. 7) (Mamounas et al., 2000; Dawson et al., 2001). Infusions of BDNF $(0.25 \mu \mathrm{g})$ into the dentate gyrus significantly increased immunolabeling for this neurotrophic factor in the area surrounding the injection site (Fig. 7). Increased BDNF immunolabeling was observed as early as 30 min after infusion, was most widespread after $2 \mathrm{hr}$, and was still present 24 
Dentate gyrus
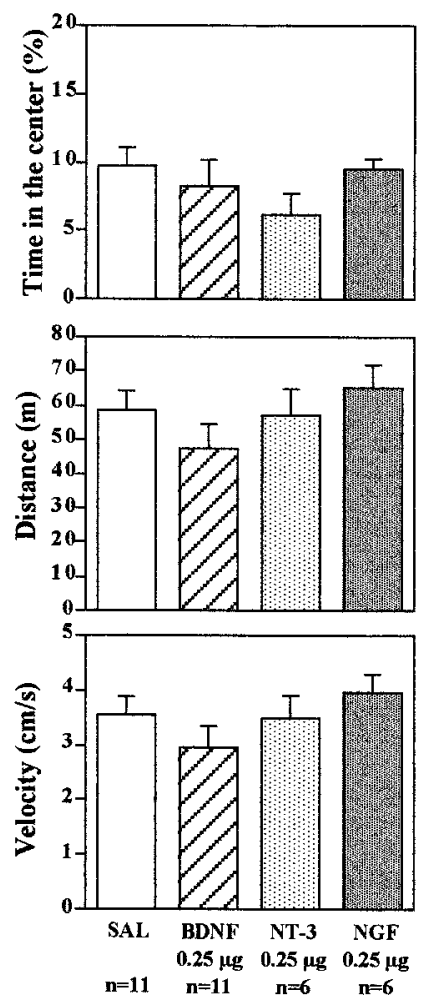

CA3
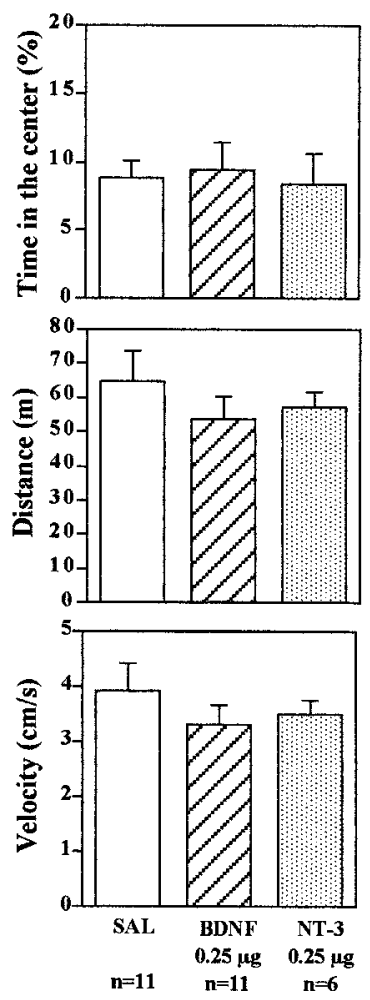

Figure 5. Influence of neurotrophic factor infusion into the hippocampus on locomotor activity. BDNF, NT-3, NGF, or saline $(S A L)$ was infused into the dentate gyrus or CA3, and $3 \mathrm{~d}$ later the times in center, distance, and velocity in an open field were determined. The results are the mean \pm SEM of the number of animals indicated under each column. Left top, Time in the center, $F_{(3,30)}=1.285 ; p=0.2973$; left middle, distance, $F_{(3,30)}=1.143 ; p=0.3479$; left bottom, velocity, $F_{(3,30)}=1.129$; $p=0.3529 ;$ right top , time in the center, $F_{(2,15)}=0.073 ; p=0.9295$; right middle, distance, $F_{(2,15)}=0.650 ; p=0.5359$; right bottom, velocity, $F_{(2,15)}=0.635 ; p=0.5438$.

hr later. By $72 \mathrm{hr}$ after infusion, when behavioral testing was conducted, there was little or no evidence of elevated BDNF immunolabeling. At the $2 \mathrm{hr}$ time point, the diffusion of BDNF was $\sim 0.5 \mathrm{~mm}$ in both the lateral (Fig. 7) and the rostrocaudal (data not shown) planes from the site of injection. Diffusion did not reach into the CA3 and CA1 subfields even when higher doses of BDNF $(1.0 \mu \mathrm{g})$ were inf used (Fig. 7).

One of the intracellular pathways known to mediate the actions of neurotrophic factors is the MAP kinase cascade, and the phosphorylation of ERK (pERK) is a key step in this cascade (Chang and Karin, 2001; Sweatt, 2001). As one measure of the functional state of the MAP kinase cascade and the response to infusion of BDNF, the level of pERK immunoreactivity was determined. In saline-inf used animals, very low levels of pERK were observed, consistent with previous reports (Sgambato et al., 1998). Infusion of BDNF increased levels of pERK immunolabeling in dentate gyrus (Fig. 8). In addition, increased pERK immunolabeling was observed in the CA3 as well as CA1 subfields (Fig. 8). The pERK immunolabeling was found primarily in the neuronal processes, although staining was also observed in cell bodies to a lesser extent (Fig. 8). These results demonstrate that BDNF infused into the hippocampus activates the MAP kinase pathway and that the effect spreads to CA3 and CA1 subfields. The latter could result from activity of BDNF at CA3 and CA1 dendrites that extend to the dentate gyrus or via activation of the mossy fiber pathway to CA3 and then Schaffer colaterals to CA1 pyramidal cell layers. In any case, this could explain, in part, why local infusion of BDNF into a specific subfield of hippocampus results in a behavioral effect similar to that produced by systemic administration of chemical antidepressants.

To further examine the functional response to BDNF infusions at a cellular level, the expression of Fos immunoreactivity was examined. Activation of the MAP kinase pathway increases c-Fos gene expression via phosphorylation of Elk-1, a transcription factor that activates the c-Fos promotor (Chang and Karin, 2001; Sweatt, 2001). Infusion of BDNF into the dentate gyrus significantly increased levels of Fos immunoreactivity in the granule cell layer, as well as in the CA3 and CA1 pyramidal cell layers (Fig. 9). The upregulation appears to be a result of an increase in the number of Fos-immunopositive cells as well as the amount of Fos per cell. The results provide further evidence that BDNF infusion produces functional activation of the MAP kinase pathway.
D1

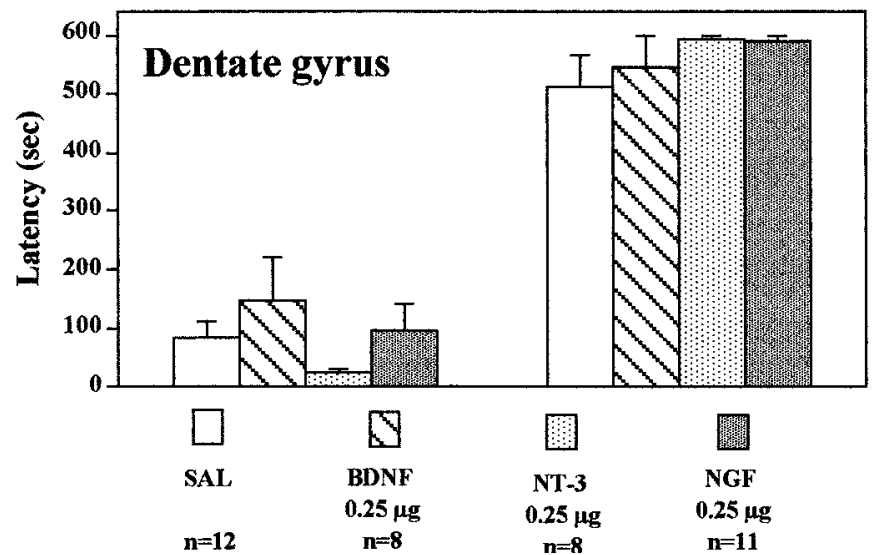

D1

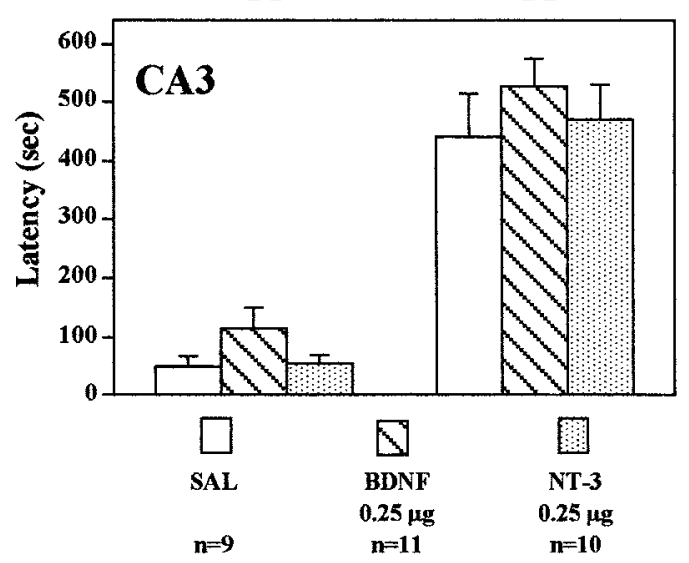

Figure 6. Influence of neurotrophic factor infusions into hippocampus on passive avoidance. BDNF, NT-3, NGF, or saline ( $S A L)$ was infused into the dentate gyrus or CA3, and 3 d later, passive avoidance testing was conducted as described in Materials and Methods. The results are mean \pm SEM of the number of animals indicated under each column. Left, Day $1(D 1), F_{(3,35)}=1.069 ; p=0.3746$; day $2(D 2), F_{(3,35)}=0.962 ; p=0.4217 ;$ right, $D 1$, $F_{(2,27)}=1.980 ; p=0.1577 ; D 2, F_{(2,27)}=0.520 ; p=0.6002$. 


\section{Inhibition of tyrosine kinase or MEK blocks the antidepressant effect of BDNF}

The neurobiological actions of neurotrophic factors are mediated by activation of the intracellular tyrosine kinase domain of their receptors, TrkA, TrkB, and TrkC for NGF, BDNF, and NT-3, respectively. If the influence of the neurotrophic factors on performance in the $\mathrm{LH}$ paradigm occurs via activation of their respective receptors, then inhibition of tyrosine kinase activity should block this effect. This possibility was tested by administration of a broad-spectrum tyrosine kinase inhibitor, K252a (Tapley et al., 1992; MacKintosh and MacKintosh, 1994). After IES training, the tyrosine kinase inhibitor was coadministered bilaterally with BDNF into the dentate gyrus, and 3 d later, animals were exposed to the conditioned avoidance test as described above. A very low dose of K252a ( $0.5 \mathrm{ng} / \mathrm{side})$ was chosen on the basis of previous work with this compound (Pizzorusso et al., 2000). The results demonstrate that K252a coadministration completely blocks the effect of BDNF on escape behavior (Fig. 10); that is, animals that have been exposed to IES and receive inf usions of K252a demonstrate the same escape deficit, although they have received infusions of BDNF. In contrast, escape performance was significantly improved in animals receiving infusions of vehicle plus BDNF.

To directly examine the role of the MAP kinase cascade in the actions of BDNF, we next tested the effect of an inhibitor of MEK, which phosphorylates and activates ERK (Chang and Karin, 2001; Sweatt, 2001). After IES, a selective MEK inhibitor, U0126, was infused into the granule cell layer $20 \mathrm{~min}$ before inf usion of BDNF. A low dose of U0126 (0.1 $\mu \mathrm{g} /$ side $)$ was chosen on the basis of previous in vivo studies using this inhibitor (Han and Holtzman, 2000; Kuroki et al., 2001). U0126 pretreatment alone did not influence responding in the conditioned avoidance test (Fig. 10). However, U0126 pretreatment completely blocked the effect of BDNF on failure number and latency to escape, similar to the effect of K252a. In addition to blockade of the behavioral effects of BDNF, infusion of U0126 completely blocked the induction of pERK (Fig. 11). Taken together, the results suggest that BDNF regulation of $\mathrm{LH}$ behavior is mediated by activation of MEK and the MAP kinase cascade.

\section{DISCUSSION}

Recent basic and clinical studies provide evidence for a neurotrophic hypothesis of depression and antidepressant action. According to this hypothesis, decreased expression of BDNF could contribute to the atrophy of hippocampus in response to stress in depressed patients, and upregulation of BDNF could contribute to the action of antidepressant treatment (Duman et al., 1997, 2000). The results of the present study provide further support for this hypothesis, demonstrating that infusion of BDNF into the hippocampus produces an antidepressant effect in two standard behavioral models of depression.

The antidepressant actions of BDNF infusions were dosedependent, long-lasting, and region- and neurotrophic factorspecific. Doses as low as $0.25 \mu \mathrm{g}$ of BDNF produced a maximal effect in both LH and FST. The effects of BDNF were observed $3 \mathrm{~d}$ after infusion and lasted up to $10 \mathrm{~d}$, indicating that BDNF produces long-term and persistent adaptations that underlie the antidepressant behavioral responses. A similar long-lasting effect

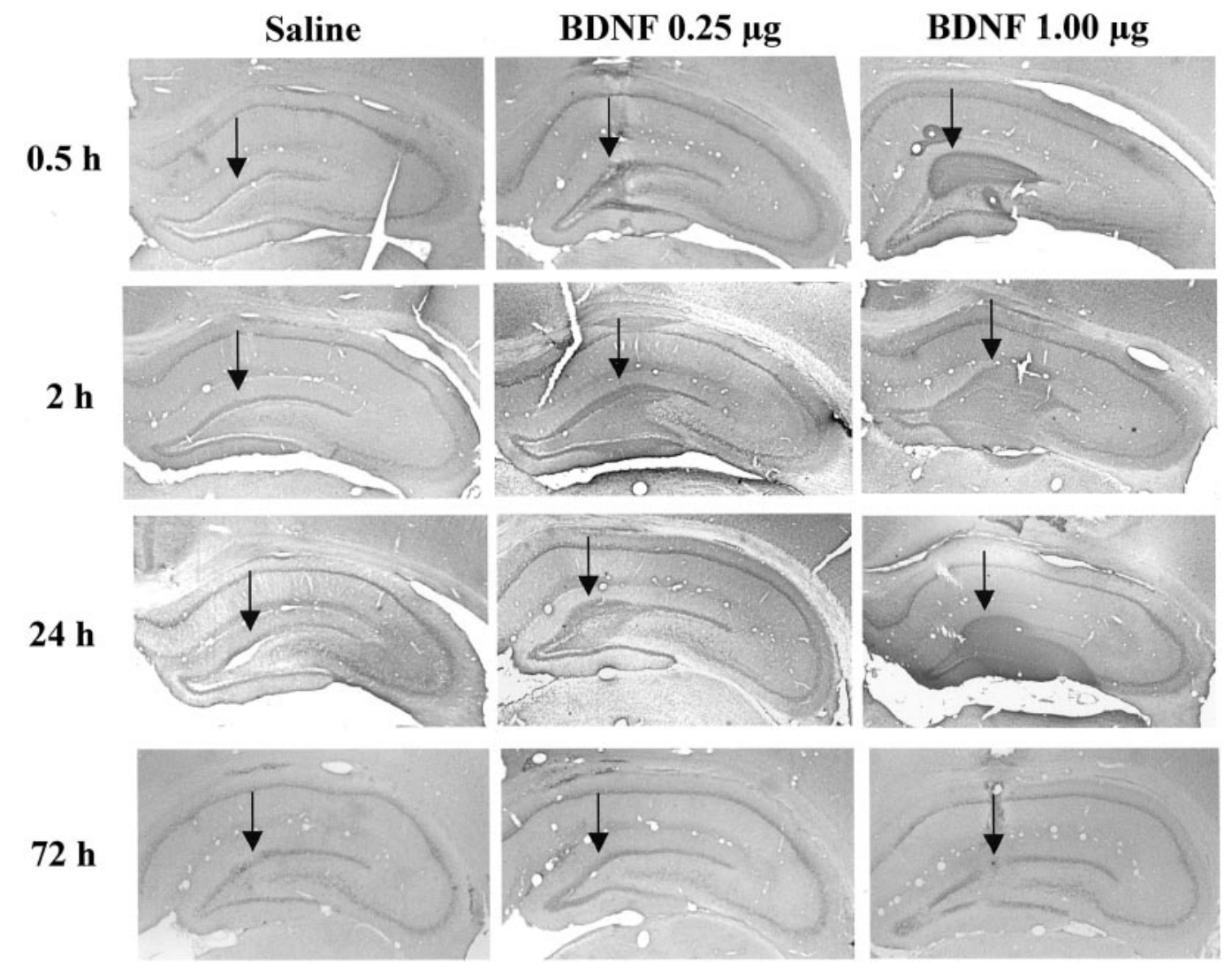

Figure 7. BDNF immunohistochemistry after local infusion into the hippocampus. BDNF $(0.25$ or $1.0 \mu \mathrm{g})$ was infused into the dentate gyrus, and BDNF immunolabeling was determined at the time points indicated. Representative sections are shown for each time point and dose of BDNF. Arrows indicate the sites of infusion. Similar effects were observed in three or four separate animals for each condition. 


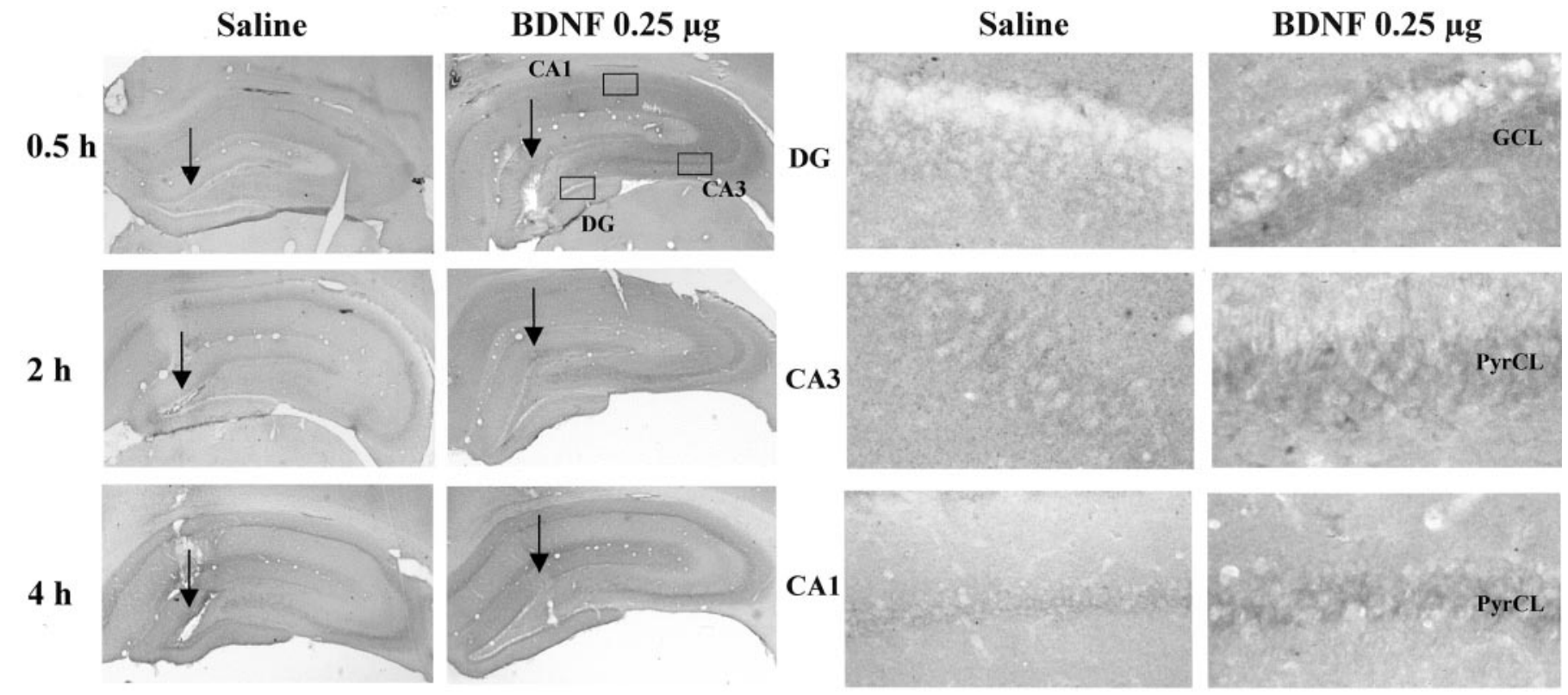

Figure 8. Influence of BDNF infusion on levels of phospho-ERK immunolabeling. BDNF $(0.25 \mu \mathrm{g})$ was infused into the dentate gyrus, and phospho-ERK immunolabeling was determined at the time points indicated. Representative low-power (left panels) and high-power (right panels) sections are shown for each time point. The locations of the dentate gyrus $(D G)$ and CA3 and CA1 pyramidal cell layers $(P y r C L)$ are indicated. Arrows indicate the infusion sites. Similar effects were observed in three or four separate animals for each condition.

on the LH and FST was observed after transient expression of cAMP response element-binding protein in the dentate gyrus (Chen et al., 2001). Differential expression of the neurotrophic factor receptors TrkA, TrkB, and TrkC in hippocampal subfields could account for the neurotrophic factor and regional specificity. For example, TrkA expression is extremely low in all subfields of hippocampus, so it is not surprising that infusions of NGF had no effect in the models tested (Merlio et al., 1993; Ueyama et al., 1997). The lack of effect of NGF provides an excellent control for these studies, because it has approximately the same molecular weight and similar structure as BDNF and NT-3.

TrkB and its ligand BDNF are expressed at relatively high levels in dentate gyrus and CA3 pyramidal cell layers, and this could account for the behavioral effects of this neurotrophic factor in both subfields (Merlio et al., 1993; Ueyama et al., 1997). TrkC and NT-3 are also expressed in the dentate gyrus, where NT-3 infusion produced a behavioral response in both LH and FST. However, TrkC but not NT-3 is also expressed in the CA3 pyramidal cell layer, suggesting that expression of the appropriate Trk receptor is not the only factor that determines a behavioral response. The latter conclusion is further supported by the presence of TrkB expression in CA1, where there was no effect of BDNF. It is possible that subcellular localization (i.e., cell body vs processes) of Trk receptors or differential expression of the intracellular signaling machinery necessary to respond to receptor activation contributes to the observed selectivity.

Several additional tests were conducted to determine whether BDNF infusions into hippocampus result in other behavioral effects. Infusion of BDNF into the dentate gyrus or CA3 pyramidal cell layer did not influence the distance traveled or the time spent in the center of a novel open field, indicating that there is not a general effect on locomotor activity. Open field activity is also a measure of anxiety, but studies of additional models of anxiety will be required to further characterize the effect of BDNF on this behavior. There was also no effect of BDNF

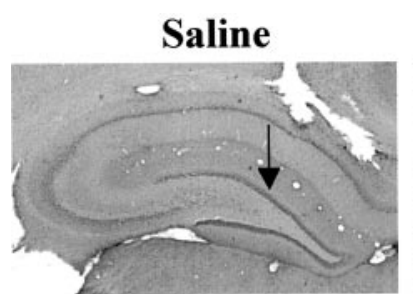

BDNF $0.25 \mu \mathrm{g}$
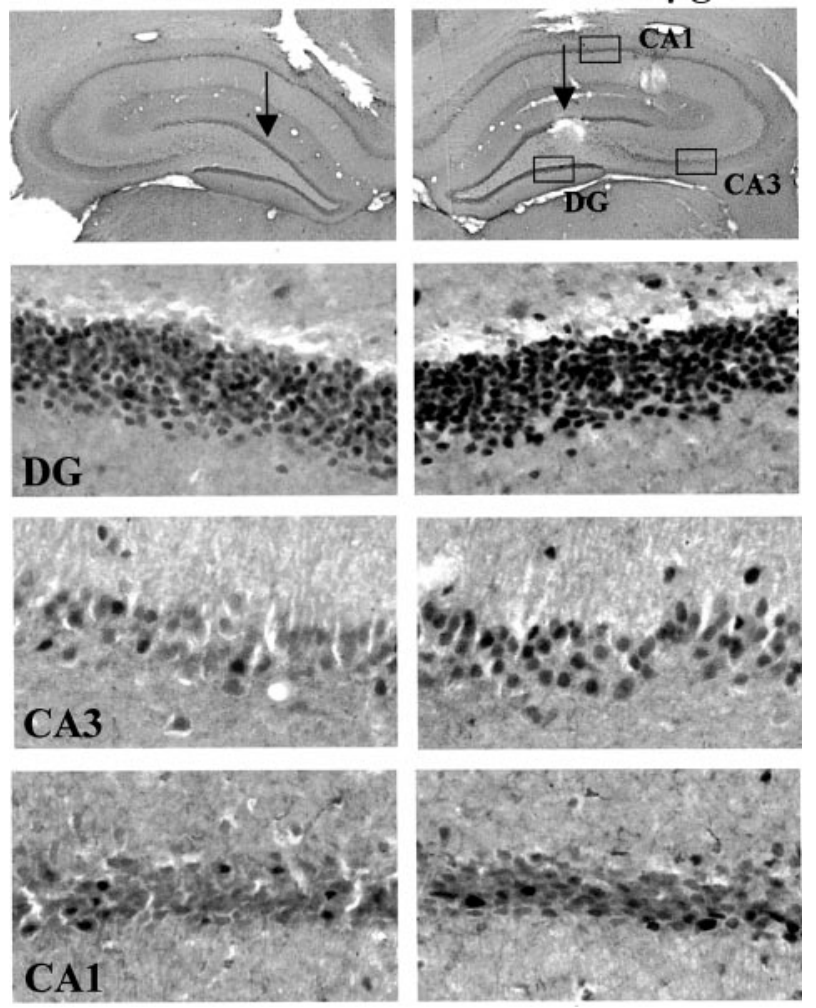

Figure 9. Influence of BDNF infusion on levels of Fos immunolabeling. BDNF $(0.25 \mu \mathrm{g})$ was infused into the dentate gyrus, and Fos immunolabeling was determined $4 \mathrm{hr}$ later. Representative sections are shown, and similar effects were observed in three or four separate animals for each condition. The locations of the dentate gyrus $(D G)$ and CA3 and CA1 pyramidal cell layers are indicated. 

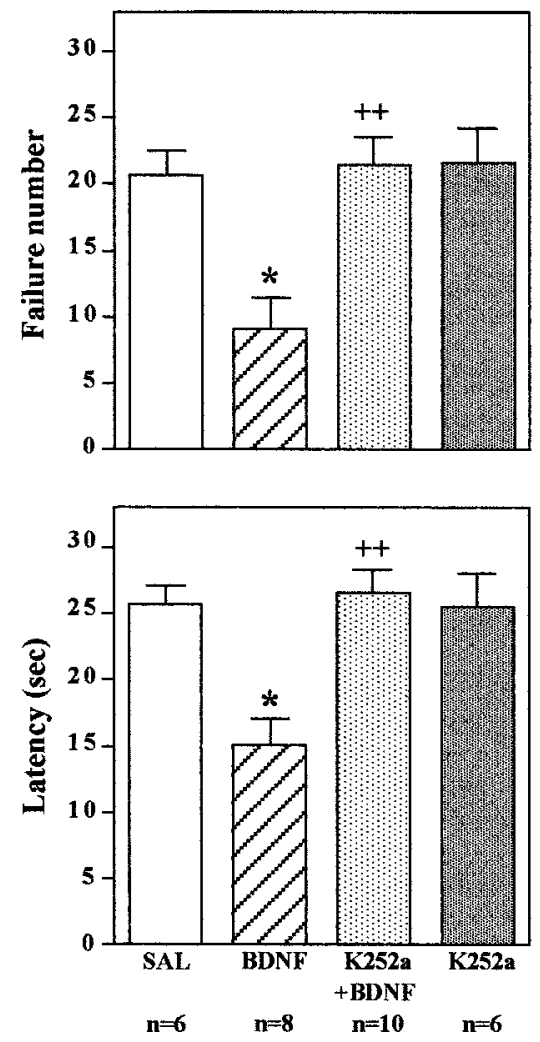
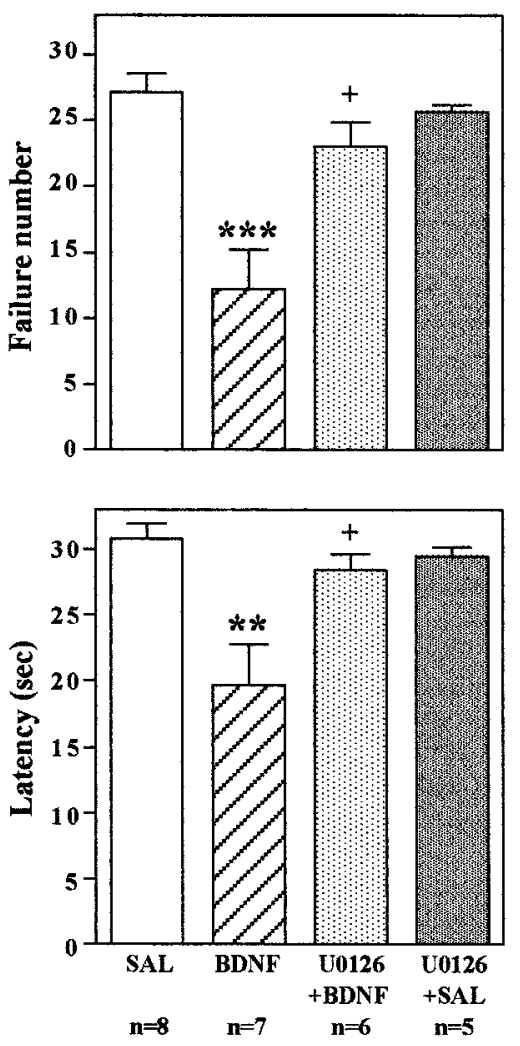

Figure 10. Infusion of K252a or U0126 blocks the effect of BDNF on conditioned avoidance. $\mathrm{LH}$ was conducted as in previous experiments; K252a was co-infused with BDNF, or U0126 was preinfused before BDNF into the dentate gyrus; and conditioned avoidance was conducted $3 \mathrm{~d}$ later. Escape failure and latency to escape were determined, and the results are expressed as mean \pm SEM. The number of animals is listed under each column. ${ }^{*} p<0.05 ;{ }^{*} p<0.01$; ${ }^{* * *} p<0.001$ when compared with saline-injected controls; ${ }^{+} p<0.05$; ${ }^{++} p<0.01$ when compared with the BDNFinjected group (ANOVA and Scheffe's test). Left top, $F_{(3,26)}=7.586 ; p=0.0008$; left bottom, $F_{(3,26)} \stackrel{=}{=} 8.177 ; p=0.0005 ;$ right top, $F_{(3,22)}=$ $10.804 ; p=0.0001$; right bottom, $F_{(3,22)}=7.432$; $p=0.0013$. infusions on passive avoidance training. However, one problem with this test is that the animals receiving saline infusions perform at near-maximal levels, so it is not possible to conclude that BDNF does not improve learning in this paradigm. However, this test does provide a good control for the LH paradigm, because the animals must stay in the compartment where they are placed, which is opposite to the response produced by BDNF in the LH paradigm (i.e., animals cross over to the other compartment to escape foot shock). It will be important to conduct additional tests to further characterize the behavioral effects of BDNF in hippocampus. For example, we are currently testing the influence of
BDNF on context and cued fear conditioning as a measure of hippocampal-dependent and -independent learning, respectively.

The area of hippocampus influenced by neurotrophic factor infusion was examined by immunohistochemical analysis of BDNF. Peak levels of BDNF immunolabeling were observed $2 \mathrm{hr}$ after infusion and lasted for up to $24 \mathrm{hr}$. By $72 \mathrm{hr}$, there was little or no evidence of the exogenous BDNF, providing additional evidence of long-term adaptations that persist after the neurotrophic factor returns to basal levels. However, it is possible that trace amounts of BDNF still exist when behavioral testing occurs. The diffusion of BDNF from the site of infusion was limited

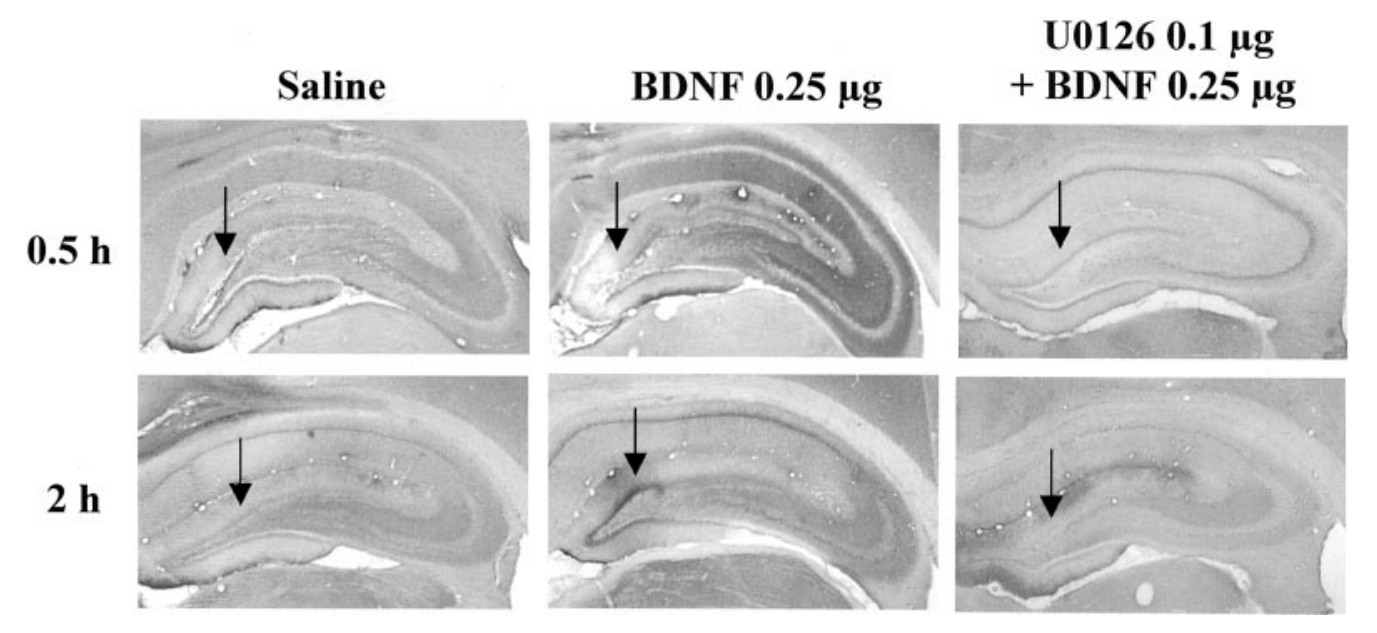

Figure 11. Influence of U0126 on the induction of pERK in hippocampus. Saline or U0126 was infused 20 min before inf usion of BDNF (0.25 $\mu \mathrm{g})$ into the dentate gyrus. Phospho-ERK immunolabeling was determined at the time points indicated. Arrows indicate the sites of infusion. Representative sections are shown for each time point and condition. The locations of the dentate gyrus $(D G)$ and CA3 and CA1 pyramidal cell layers $(P y r C L)$ are indicated. Similar effects were observed in three or four separate animals for each condition. 
( $\sim 0.5 \mathrm{~mm})$, suggesting that BDNF injections into additional sites might produce a more robust antidepressant effect. However, bilateral infusions at three different rostrocaudal levels into the dentate gyrus did not result in a significantly greater effect than infusion at a single level.

The reason that a single infusion produces an effect similar to that of multiple infusions may be explained by the finding that the functional response to BDNF is more widespread than BDNF immunolabeling. Induction of pERK and Fos immunoreactivity is taken as a measure of activation of the MAP kinase cascade, one of the primary intracellular pathways stimulated by BDNF and TrkB (Chang and Karin, 2001; Sweatt, 2001). ERK is a key mediator of the MAP kinase pathway, and the activity of this kinase is regulated by phosphorylation. There are many cellular proteins that are regulated by ERK, including the gene transcription factor Elk-1, and one of the gene targets of Elk-1 and the MAP kinase cascade is Fos. Infusion of BDNF into dentate gyrus increased pERK immunolabeling in the surrounding area of the dentate gyrus, as well as in CA3 and CA1 pyramidal cell layers. Similarly, we found that Fos immunoreactivity was upregulated in the dentate gyrus and CA3 and CA1 pyramidal cell layers by infusion of BDNF into the dentate gyrus.

The induction of pERK and Fos by BDNF distal to the infusion site could occur via one of several mechanisms. One possibility is that the dendritic fields of CA 3 and CA1 pyramidal cells extend far enough to be influenced by the spread of BDNF from the dentate gyrus. These pyramidal cells have extensive dendritic processes with an estimated total dendritic length of 13-16 mm. More than $20 \%$ of the processes are in the stratum lacunosummoleculare, the terminal region of the perforant pathway where the dendritic tree of the granule cells also extends (Amaral and Witter, 1995). Another possibility is that the induction of pERK and Fos occurs in response to BDNF modulation of neurotransmission. There are numerous reports of neurotrophic factormediated enhancement of synaptic transmission, primarily via modulation of presynaptic transmitter release but also by modulation of postsynaptic sites (Poo, 2001). In addition, a recent study demonstrated that neurotrophic factors can cause membrane depolarization via TrkB activity-dependent regulation of a novel sodium channel (Kafitz et al., 1999). The induction of both pERK and Fos is known to be activity-dependent, and the response to BDNF could result from enhancement of synaptic transmission or depolarization of granule cells. Enhanced synaptic activity in the granule cell layer could then spread to CA3 via the mossy fiber pathway and to CA1 via Schaffer collaterals. BDNF could also increase synaptic activity of CA3 and CA1 pyramidal cells via regulation of synaptic transmission at dendrites that extend to the dentate gyrus as discussed above. Regardless of the mechanism, induction of pERK and Fos demonstrates that BDNF infusion produces a functional activation of the MAP kinase pathway that could contribute to the effects of BDNF in the LH and FST paradigms.

The induction of pERK and Fos suggests that the behavioral effects of BDNF could occur via activation of Trk receptors and the MAP kinase cascade. To test this possibility the influence of a broad-spectrum protein kinase inhibitor, K252a, was determined. Co-infusion of K252a with BDNF into the dentate gyrus completely abolished the antidepressant effect of BDNF in the LH paradigm. K252a is an inhibitor of receptor-tyrosine kinases, and these results are consistent with the possibility that activation of Trk receptors is required for the actions of BDNF. However, $\mathrm{K} 252 \mathrm{a}$ also inhibits other classes of tyrosine kinase receptors, as well as Ser/Thr kinases, including those in the MAP kinase cascade (MacKintosh and MacKintosh, 1994). To further examine the role of the MAP kinase cascade, we also tested the effect of a selective inhibitor of MEK, the kinase responsible for activation of ERK. Infusion of U0126 completely blocked the effect of BDNF on escape behavior in the $\mathrm{LH}$ paradigm as well as the induction of pERK. These results provide additional evidence that activation of $\mathrm{MEK}$ and ERK are necessary for the antidepressant-like effects of BDNF in the LH behavioral model.

There are several possible neurobiological mechanisms that could contribute to the antidepressant effects of BDNF, including regulation of synaptic plasticity and learning and memory. The $\mathrm{LH}$ paradigm is thought to result from the learning and memory of a stressful experience, and modulation of these processes could influence responding in the conditioned avoidance test. Studies of long-term potentiation (LTP), a cellular model of learning and memory, suggest that BDNF is necessary, but not sufficient, for both the early and late phases of LTP (Poo, 2001). Therefore, inf usion of BDNF several days after exposure to stress should not influence the memories that have already been formed. However, it is possible that enhancement of the learning and memory of new experiences or modulation of hippocampal synaptic transmission by BDNF could interfere with the memory of the stressful experience and thereby result in an antidepressant effect. Another possibility is that BDNF makes hippocampal neurons more resilient and able to oppose the effects of stress (e.g., oppose the downregulation of neurotrophic factor support, inhibit potential excitoxic damage, and block neuronal atrophy; Duman et al., 2000; McEwen, 2000; Sapolsky, 2000). The ability of BDNF to increase neuronal survival, function, and synaptic remodeling is consistent with this possibility (McAllister et al., 1999; Poo, 2001). Future studies will be needed to further identify the molecular and cellular adaptations that underlie the actions of BDNF and how these adaptations translate into antidepressant effects at a systems level.

\section{REFERENCES}

Altar C (1999) Neurotrophins and depression. Trends Pharmacol Sci 20:59-61.

Amaral D, Witter MP (1995) Hippocampal formulation. In: The rat nervous system: hippocampal formulation, Ed 2 (Paxinos $G$, ed). San Diego: Academic.

Bremner J, Narayan M, Anderson ER, Staib LH, Miller H, Charney DS (2000) Smaller hippocampal volume in major depression. Am J Psychiatry $157: 115-117$

Chang L, Karin M (2001) Mammalian MAP kinase signalling cascades. Nature 410:37-40.

Chen A-H, Shirayama Y, Shin K-H, Neve RL, Duman RS (2001) Expression of the cAMP response element binding protein (CREB) in hippocampus produces antidepressant effect. Biol Psychiatry 49:753-762.

Dawson N, Hamid EH, Egan MF, Meredith GE (2001) Changes in the pattern of brain-derived neurotrophic factor immunoreactivity in the rat brain after acute and subchronic haloperidol treatment. Synapse 39:70-81.

Duman R, Heninger GR, Nestler EJ (1997) A molecular and cellular theory of depression. Arch Gen Psychiatry 54:597-606.

Duman R, Malberg J, Nakagawa S, DíSa C (2000) Neuronal plasticity and survival in mood disorders. Biol Psychiatry 48:732-739.

Dwivedi Y, Rizavi HS, Roberts RC, Conley RC, Tamminga CA, Pandey GN (2001) Reduced activation and expression of ERK1/2 MAP kinase in the post-mortem brain of depressed suicide subjects. J Neurochem 77:916-928.

Ferry B, Roozendaal B, McGaugh JL (1999) Basolateral amygdala noradrenergic influences on memory storage are mediated by an interaction between $\beta$ - and $\alpha_{1}$-adrenoceptors. J Neurosci 19:5119-5123.

Han BH, Holtzman DM (2000) BDNF protects the neonatal brain from hypoxic-ischemic injury in vivo via the ERK pathway. J Neurosci 20:5775-5781.

Kafitz K, Rose CR, Thoenen H, Konneth A (1999) Neurotrophinevoked rapid excitation through TrkB receptors. Nature 401:918-921. 
Kessler R, McGonagle KA, Zhao S, Nelson CB, Hughes M, Eshleman S, Wittchen H, Kendler KS (1994) Lifetime and 12-month prevalence of DSM-III-R psychiatric disorders in the United States: results from the national comorbidity survey. Arch Gen Psychiatry 51:8-19.

Kuroki Y, Fukushima K, Kanda Y, Mizuno K, Watanabe Y (2001) Neuroprotection by estrogen via extracellular signal-regulated kinase against quinolinic acid-induced cell death in the rat hippocampus. Eur J Neurosci 13:472-476.

Lacroix L, Broersen LM, Weiner I, Feldon J (1998) The effects of excitotoxic lesion of the medial prefrontal cortex on latent inhibition, prepulse inhibition, food hoarding, elevated plus maze, active avoidance and locomotor activity in the rat. Neuroscience 84:431-442.

Lucki I (1997) The forced swimming test as a model for core and component behavioral effects of antidepressant drugs. Behav Pharmacol 8:523-532.

MacKintosh C, MacKintosh RW (1994) Inhibitors of protein kinases and phosphatases. Trends Biochem Sci 19:444-448.

Maier S (2001) Exposure to the stressor environment prevents the temporal dissipation of behavioral depression/learned helplessness. Biol Psychiatry 49:763-773.

Mamounas L, Altar CA, Blue ME, Kaplan DR, Tessarollo L, Lyons WE (2000) BDNF promotes the regenerative sprouting, but not survival, of injured serotonergic axons in the adult rat brain. J Neurosci 20:771-782.

Manji H, Moore GJ, Chen G (2000) Clincial and preclinical evidence for the neurotrophic effects of mood stabilizers: implications for the pathophysiology and treatment of manic-depressive illness. Biol Psychiatry 48:740-754.

McAllister K, Katz LC, Lo DC (1999) Neurotrophins and synaptic plasticity. Annu Rev Neurosci 22:295-318.

McEwen B (2000) Effects of adverse experiences for brain structure and function. Biol Psychiatry 48:721-731.

Merlio J, Ernfors P, Kokaia Z, Middlemas DS, Bengzon J, Kokaia M, Smith M-L, Siesjo BK, Hunter T, Lindvall O, Persson H (1993) Increased production of the TrkB protein tyrosine kinase receptor after brain insults. Neuron 10:151-164.

Nibuya M, Morinobu S, Duman RS (1995) Regulation of BDNF and trkB mRNA in rat brain by chronic electroconvulsive seizure and antidepressant drug treatments. J Neurosci 15:7539-7547.

Nibuya M, Nestler EJ, Duman RS (1996) Chronic antidepressant administration increases the expression of cAMP response element binding protein (CREB) in rat hippocampus. J Neurosci 16:2365-2372.

Nibuya M, Takahashi M, Russell DS, Duman RS (1999) Chronic stress increases catalytic TrkB mRNA in rat hippocampus. Neurosci Lett 267:81-84.

Paxinos G, Watson GC (1982) The rat brain in stereotaxic coordinates. New York: Academic

Pizzorusso T, Ratto GM, Putignano E, Maffei L (2000) Brain-derived neurotrophic factor causes cAMP response element-binding protein phosphorylation in absence of calcium increases in slices and cultured neurons from rat visual cortex. J Neurosci 20:2809-2816.

Poo M (2001) Neurotrophins as synaptic modulators. Nat Rev Neurosci 2:24-32.

Porsolt R, Le Pichon M, Jalfre M (1977) Depression: a new animal model sensitive to antidepressant treatments. Nature 266:730-732.

Rosello-Neustadt ABR, Cotman CW (1999) Exercise, antidepressant medications, and enhanced brain derived neurotrophic factor expression. Neuropsychopharmacology 21:679-682.

Sapolsky R (2000) The possibility of neurotoxicity in the hippocampus in major depression: a primer on neuron death. Biol Psychiatry 48:755-765.

Seligman M, Beagley G (1975) Learned helplessness in the rat. J Comp Physiol Psychol 88:534-541.

Sgambato V, Pages C, Rogard M, Besson M-J, Caboche J (1998) Extracellular signal-regulated kinase (ERK) controls immediate early gene induction on corticostriatal stimulation. J Neurosci 18:8814-8825.

Sheline Y, Wany P, Gado MH, Csernansky JG, Vannier MW (1996) Hippocampal atrophy in recurrent major depression. Proc Natl Acad Sci USA 93:3908-3913.

Sheline Y, Sanghavi M, Mintun MA, Gado MH (1999) Depression duration but not age predicts hippocampal volume loss in medically healthy women with recurrent major depression. J Neurosci 19:5034-5043.

Siuciak JA, Lewis DR, Wiegand SJ, Lindsay R (1997) Antidepressantlike effect of brain derived neurotrophic factor (BDNF). Pharmacol Biochem Behav 56:131-137.

Smith MA, Makino S, Kvetnansky R, Post RM (1995) Stress alters the express of brain-derived neurotrophic factor and neurotrophin-3 mRNAs in the hippocampus. J Neurosci 15:1768-1777.

Sweatt J (2001) The neuronal MAP kinase cascade: a biochemical signal integration system subserving synaptic plasticity and memory. J Neurochem 76:1-10.

Tapley P, Lamballe F, Barbacid M (1992) K252a is a selective inhibitor of the tyrosine protein kinase activity of the trk family of oncogenes and neurotrophin receptors. Oncogene 7:371-381.

Thiébot M-H, Martin P, Puech AJ (1992) Animal behavioural studies in the evaluation of antidepressant drugs. Br J Psychiatry 160:44-50.

Ueyama T, Kawai Y, Nemoto K, Sekimoto M, Tone S, Senba E (1997) Immobilization stress reduced the expression of neurotrophins and their receptors in the rat brain. Neurosci Res 28:103-110.

Weiss J, Kilts CD (1995) Animal models of depression and schizophrenia. Washington, DC: American Psychiatric.

Wong M-L, Licinio J (2001) Research and treatment approaches to depression. Nat Rev Neurosci 2:343-351. 